\title{
VHF scintillations and plasma drifts observed in southern Taiwan during the declining phase of solar cycle 24
}

\author{
Ya-Chih Mao ${ }^{1}$ and Cissi Y. Lin ${ }^{1,2, *}$ \\ ${ }^{1}$ Department of Space Science and Engineering, National Central University, Taoyuan City, Taiwan \\ ${ }^{2}$ Center for Astronautical Physics and Engineering, National Central University, Taoyuan City, Taiwan
}

Article history:

Received 29 August 2021

Accepted 16 September 2021

Keywords:

Scintillation, Plasma drift, Very high frequency sounding, Equatorial ionization anomaly

\section{Citation:}

Mao, Y.-C. and C. Y. Lin, 2021: VHF scintillations and plasma drifts observed in southern Taiwan during the declining phase of solar cycle 24 Terr. Atmos. Ocean. Sci., 32, 553-560, doi: 10.3319/TAO.2021.09.16.02

\begin{abstract}
Long-term observations of very high frequency (VHF) scintillations sounded at $244 \mathrm{MHz}$ were conducted at one of the Scintillation Network Decision Aid (SCINDA) sites in Pingtung $\left(22.6^{\circ} \mathrm{N}, 120.5^{\circ} \mathrm{E}\right.$; geomagnetic latitude $\left.12.5^{\circ} \mathrm{N}\right)$, Taiwan, in 2015 - 2019, over the declining phase of solar cycle 24. Two VHF receivers are used to derive zonal drift velocity. The responses of $\mathrm{S}_{4}$ indices, occurrences and east-west drifts are investigated with respect to local time, season, and solar activity. The results show that strong scintillations $\left(\mathrm{S}_{4}>0.5\right)$ appear frequently at early nighttime at equinoxes during the high solar activity year of 2015 , while weak scintillations $\left(\mathrm{S}_{4}\right.$ : $0.2-0.5$ ) occur often at early daytime and more frequently at early nighttime in summer without obvious correlation with solar activity levels. The peak drift of $\sim 50$ - 60 $\mathrm{m} \mathrm{s}^{-1}$ is observed eastward at night and westward during the day. Stronger scintillations and higher drift velocities are observed in spring and fall.
\end{abstract}

\section{INTRODUCTION}

Scintillation involves ionospheric irregularities interfering with radio signals when radio waves are propagating through the ionosphere. The electromagnetic energy of signals is scattered and redistributed when the signals propagate through ionospheric irregularities, especially in the F-region, where ionized gas is most abundant. The phenomenon has been observed at the $10^{6}-10^{9} \mathrm{~Hz}$ frequency range (Spatz et al. 1988). Prominent scintillations often result in fading or fluctuations of communication signals below their nominal levels. Scientists observed strong scintillations in the very high frequency (VHF) and L bands in the equatorial ionization anomaly (EIA) region during post-sunset hours (Basu et al. 1987; Wiens et al. 2006; McNamara et al. 2013; Olwendo et al. 2013; Liu et al. 2016; Chen et al. 2017; Seif et al. 2017; Bhattacharyya et al. 2019). Based on global observations of GPS radio occultation, Liu et al. (2016) reported that strong L-band scintillations appear within the low-latitude region of $\pm 30^{\circ} \mathrm{N}$, centering around $\pm 20^{\circ} \mathrm{N}$ magnetic latitude. The scintillations onset at 1900

\footnotetext{
* Corresponding author

E-mail: cissi@g.ncu.edu.tw
}

LT (local time), reached the maximum at $2100 \mathrm{LT}$, and vanished by 0200 - 0300 LT. Liu et al. (2016) further found that the equatorial/low-latitude scintillations during 2000 $0100 \mathrm{LT}$ intensified in the equinox months compared to other seasons. Using VHF-, UHF-, and L-band signals, Basu et al. (1988) found that the occurrence of scintillations highly depends on solar activity. The results agree with the finding that occurrence rate of irregularities has a positive correlation with solar activity (Ackah et al. 2011; Liu et al. 2016; Chen et al. 2017; Singh et al. 2017). Groves et al. (1997) deployed two stations spaced latitudinally to observed scintillations for an empirical plasma bubble model, which generates three-dimensional maps of ionospheric irregularities for communication outage warning. Using 10 years of VHF data, Prasad et al. (2012) recorded the scintillation for the entire solar cycle 23 and concluded that scintillations are inhibited during geomagnetically disturbed days. Meanwhile, simultaneous observations of amplitude scintillations at spaced locations by receiving VHF beacon and/or L-band signals from geostationary and GPS satellites have been employed to investigate zonal drift in the equatorial ionosphere (Basu et al. 1996; Valladares et al. 2002; Otsuka 
et al. 2006; Wiens et al. 2006; Ji et al. 2011; Andima et al. 2018). Based on prominent scintillations, they found that horizontal plasma flows are about $50-150 \mathrm{~m} \mathrm{~s}^{-1}$ eastward during 2000 - 0400 LT.

The Scintillation Network Decision Aid (SCINDA) is one of the most comprehensive radio receiver groundbased systems designed for scintillation observations. The network comprises sites distributed globally with local cooperators helping maintenance of the sites. The purpose of SCINDA is not only to focus on the specification and prediction of satellite communication degradation due to ionospheric scintillation, but also to facilitate scientific studies on the geomagnetic equatorial region (Ackah et al. 2011; McNamara et al. 2013; Andima et al. 2018). A SCINDA site contains GPS and VHF receivers and antennas and receives signals from geostationary satellites at an altitude of approximately $35000 \mathrm{~km}$ above mean sea level. Though scintillations and drifts in the equatorial ionosphere have been well studied (Spatz et al. 1988; Basu et al. 1996; Kil et al. 2002; Otsuka et al. 2006; Wiens et al. 2006; Olwendo et al. 2013; Joshi et al. 2019), the events in the EIA have not yet been explored much. In this study, the diurnal, seasonal, and solar activity variations of VHF scintillations and drifts in the EIA ionosphere observed by the SCINDA site in Pingtung $\left(22.6^{\circ} \mathrm{N}, 120.5^{\circ} \mathrm{E}\right.$; geomagnetic latitude $\left.12.5^{\circ} \mathrm{N}\right)$ in 2015 - 2019 during the declining phase of Solar Cycle 24 are examined in detail.

\section{METHODOLOGY}

The two VHF receivers at the SCINDA site in Pingtung $\left(22.6^{\circ} \mathrm{N}, 120.5^{\circ} \mathrm{E}\right.$; dip latitude $\left.12.5^{\circ}\right)$ of southern Taiwan are equipped with Yagi-Uda antennas, observing signals from geostationary satellites at $244 \mathrm{MHz}$. Figure 1a shows the geolocation of the site, which is near the northern crest of EIA. The two receivers are separated by $72 \mathrm{~m}$ (Joshi et al. 2019) in the east-west orientation as shown in Fig. 1b, an ideal setup for investigating east-west plasma drifts. The receiver to the west is labeled as Channel 1 and the receiver to the east is labeled as Channel 0 .

The data included in this study is from 2015 to 2019 . Some components at the observation site were damaged by severe weather in 2018, resulting in missing data during the second half of the year. Overall, the data set in this study covers 360 days of 2015, 360 days of 2016, 355 days of 2017,176 days of 2018, and 360 days of 2019. Table 1 tabulates the numbers of days when the VHF observations are available for scintillation and drift estimations by season. Insufficient data for the estimation of drifts resulted from occasional hardware or software failures at one of the receivers, which also led to overall lower numbers of observation days in summer and fall as shown in Table 1. Nevertheless, the comparison between summer and winter shows that less observation days do not necessarily result in less days for drift estimations. In the $4^{\text {th }}$ and $5^{\text {th }}$ columns of Table 1 list the numbers of days with drift estimations and the numbers of drift data points, respectively. The detailed daytime and nighttime statistics are also shown. Clearly, the higher the available days of observations does not necessarily suggest the higher drift data points. Between the two receivers, the distribution of overall 10317 1-min drift data includes 6353 points in spring, 1776 points in summer, 1313 points in fall, and 875 in winter. Table 1 shows that the SCINDA data set collected in Pingtung, Taiwan is well-balanced and is qualified for seasonal and diurnal studies of scintillation and plasma drifts.

\subsection{Scintillation and the $S_{4}$ Index}

The $\mathrm{S}_{4}$ index, a measure for scintillation, is estimated per minute with the equation (Yeh and Liu 1982; Spatz et al. 1988; Van Dierendonck et al. 1993),

$\mathrm{S}_{4}{ }^{2}=\frac{\left\langle I^{2}\right\rangle-\langle I\rangle^{2}}{\langle I\rangle^{2}}$

where $I=A^{2}$ is the intensity and $A$ is the amplitude of VHF signals. There are eight sensors on each of the receivers, measuring amplitudes of VHF signals at a time. Averages of the eight measurements are taken as final products of $S_{4}$ indices. Figure 1c demonstrates the process. In this study, we define a scintillation event as a continuous segment in time with disturbed or faded signal levels. Scintillation occurrence rate is defined as the ratio of the number of data points with scintillations to that of all the available data points during a given time interval, given that the signals came from the geostationary satellites when their elevation angles were above $30^{\circ}$. Scintillations of $\mathrm{S}_{4}$ index $<0.5$ are considered weak, and those of $S_{4}$ index $\geq 0.5$ are considered strong (Basu et al. 1996). Spotty points of $S_{4}$ index $\geq 2$, which are likely caused by bad data points or noise, are excluded from the discussion in this work. Studies has shown that weak scintillations occurred relatively frequently regardless of solar activity levels, while strong scintillations appeared to occur during high solar activity (Basu et al. 1996; Hlubek et al. 2014). Therefore, this study focuses on scintillation events with the $S_{4}$ index ranging from 0.2 to 2 . Figure $1 \mathrm{c}$ reveals that the $S_{4}$ index yields double peaks, the daytime peak at 1000 LT and the nighttime peak, while the strong (weak) scintillations reaches the maximum occurrence at 2130 (2400) LT.

\subsection{Drift Velocity}

Drift velocities are estimated per minute when two receivers were online. Applying auto-correlation and crosscorrelation (Yeh and Liu 1982; Spatz et al. 1988; Joshi et al. 

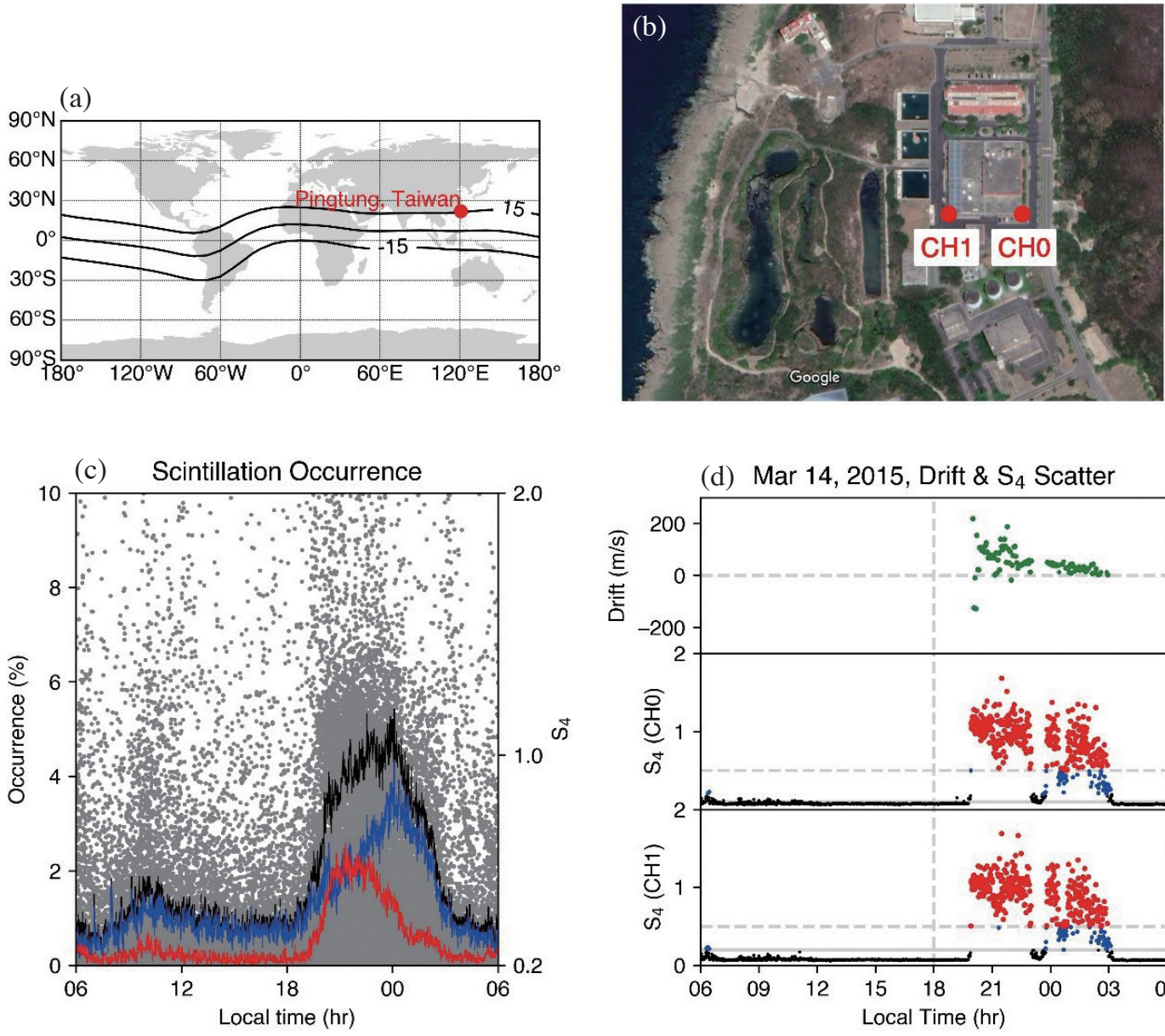

(d) Mar 14, 2015, Drift \& $S_{4}$ Scatter

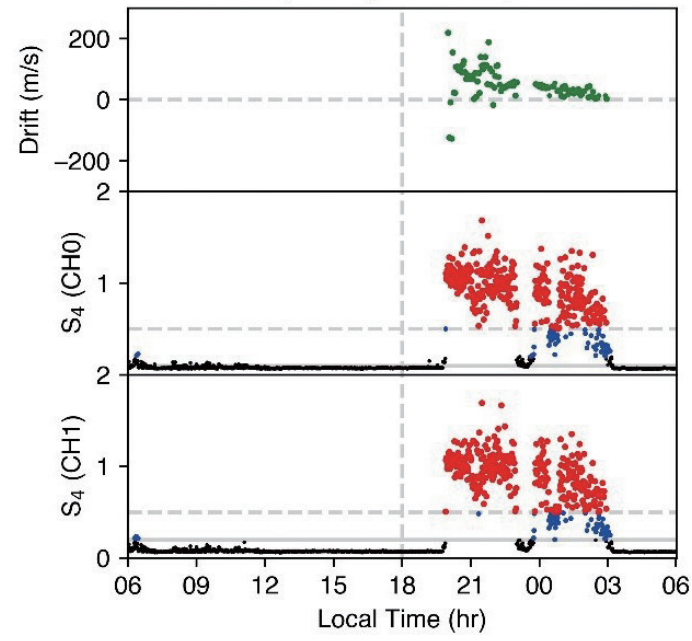

Fig. 1. (a) The Pingtung SCINDA site $\left(22.6^{\circ} \mathrm{N}, 120.5^{\circ} \mathrm{E}\right.$; dip latitude $\left.12.5^{\circ}\right)$ is located near the northern crest of EIA. (b) Two VHF receivers are spaced $72 \mathrm{~m}$ apart. (c) Diurnal variation of scintillations: $\mathrm{S}_{4}$ index (gray dots), occurrence rates of strong events (red), weak events (blue), and overall events (black). (d) An example of derived plasma drift velocity along with the scintillated VHF signals.

Table 1. Days with available observations for scintillation and drift estimations.

\begin{tabular}{|c|c|c|c|c|c|c|}
\hline \multirow[b]{2}{*}{ Spring } & \multirow{2}{*}{$\begin{array}{c}\text { Days w/both Receivers Working } \\
446\end{array}$} & \multirow{2}{*}{\begin{tabular}{|c|} 
Days w/Scintillations \\
333 \\
\end{tabular}} & \multicolumn{2}{|c|}{ Days w/Drifts } & \multicolumn{2}{|c|}{ Number of Drift Data Point } \\
\hline & & & 149 & $\begin{array}{c}\mathrm{D}: 56 \\
\mathrm{~N}: 115\end{array}$ & 6353 & $\begin{array}{c}\text { D:156 } \\
\text { N:6197 }\end{array}$ \\
\hline Summer & 398 & 382 & 192 & $\begin{array}{l}\mathrm{D}: 124 \\
\mathrm{~N}: 138\end{array}$ & 1776 & $\begin{array}{l}\mathrm{D}: 910 \\
\mathrm{~N}: 866\end{array}$ \\
\hline Fall & 368 & 332 & 128 & $\begin{array}{l}\mathrm{D}: 54 \\
\mathrm{~N}: 94\end{array}$ & 1313 & $\begin{array}{c}\text { D:153 } \\
\text { N:1160 }\end{array}$ \\
\hline Winter & 431 & 324 & 149 & $\begin{array}{l}\text { D:90 } \\
\text { N:80 }\end{array}$ & 875 & $\begin{array}{l}\mathrm{D}: 454 \\
\mathrm{~N}: 421\end{array}$ \\
\hline
\end{tabular}


2019) onto the signals provides the time lags between the signal arrivals at the two ground receivers. The drifts can then be estimated by the equation,

$V_{0}=\frac{\Delta x \cdot \tau_{m}}{\tau_{p}^{2}+\tau_{m}^{2}}$

where $\Delta x$ is the distance between the two east-west receivers, $\tau_{m}$ is the time lag at the maximum cross-correlation of the two receivers, and $\tau_{p}$ is the time lag between the peak of autocorrelations and that of cross-correlations. Positive (negative) time lags, $\tau_{m}$, indicate eastward (westward) drifts. Figure 1d shows an example of how the drifts (top) are derived from the two channels (middle: Channel 0; bottom: Channel 1). With our data set, it is found that in general drift estimation is possible on the days with scintillation, though not a necessary condition.

\section{RESULTS}

Figure 2 shows the diurnal variation of the $\mathrm{S}_{4}$ indices (right vertical axis) and scintillation occurrence rates (left vertical axis) organized by year and season. From left to right, the panels show months around solstices and equinoxes: spring (February, March, and April), summer (May,
June, and July), fall (August, September, and October), and winter (November, December, and January). The scintillation events with the $\mathrm{S}_{4}$ index of $0.2-2.0$ are represented by the scattered gray dots. The occurrence rate of all the scintillation events is shown in black. A closer examination of the $\mathrm{S}_{4}$ index reveals local-time dependency and seasonal variation of the occurrence rates. In spring and fall, strong scintillations occur most frequently at $1900-2000$ LT while weak scintillations peak at later hours, often close to midnight during 2015 - 2017. The difference between the peak hours is observed up to 5 hours, as in the cases of spring and fall of 2015. Early studies (Chandra and Rastogi 1974; Rastogi and Mullen 1981; Prasad et al. 2012) have suggested that strong and fast fading scintillations at premidnight hours were associated with range type of spread$\mathrm{F}$ and weak and slow fading scintillations at post-midnight hours were more likely associated with frequency type of spread-F. In summer, the occurrence rates of weak scintillations yield the daytime peak at $1000 \mathrm{LT}$ and the nighttime at $2400 \mathrm{LT}$, while those of strong and weak scintillations peak at around the same local hour of 2200 - 2300 LT. During 2015 - 2019, strong scintillations in summer and winter appear to diminish in a much more rapid fashion compared to those in spring and fall. The occurrence rate stays below $10 \%$ for the winter months. Overall, across the five years of observations, occurrence rates of strong scintillations lower
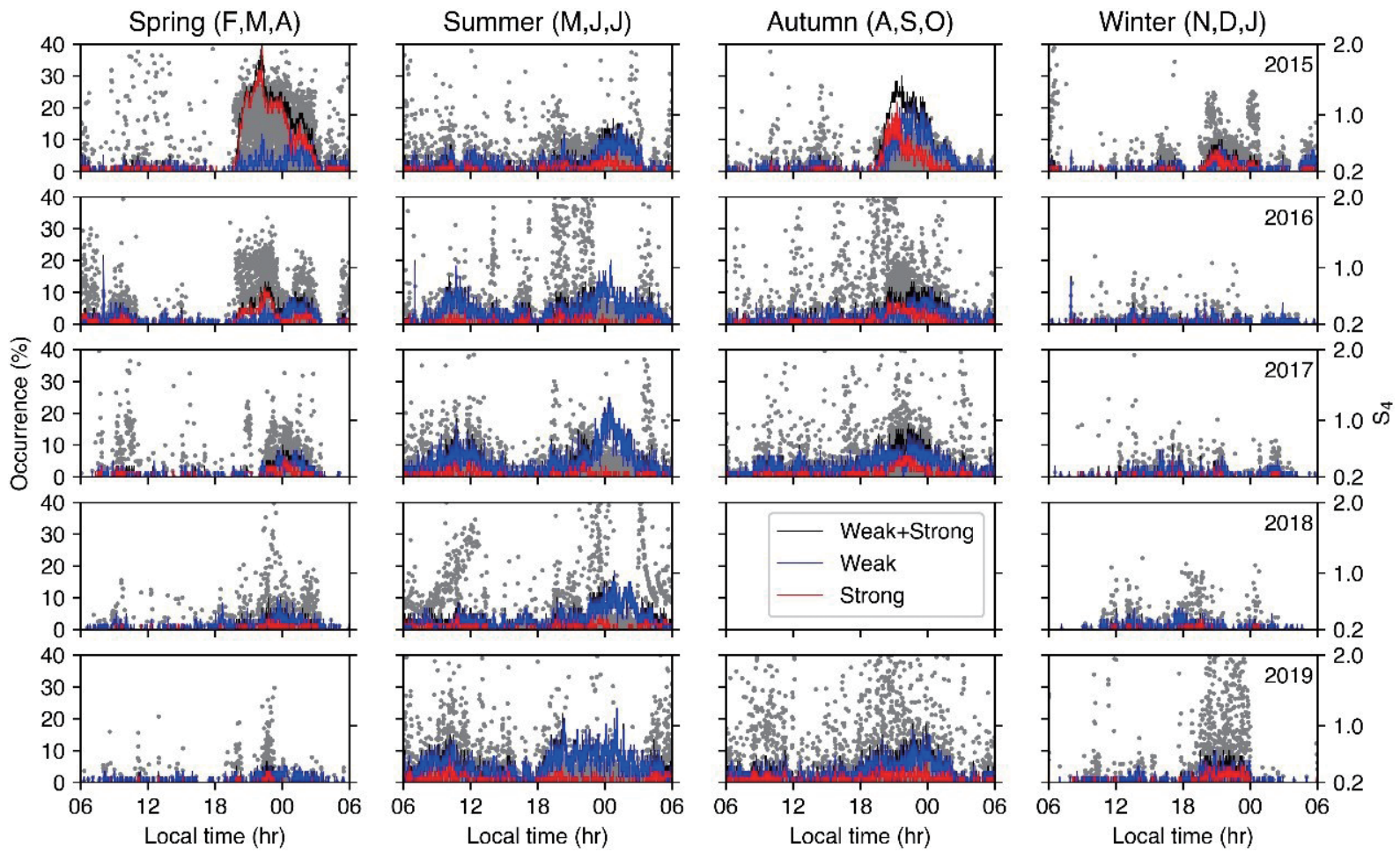

Fig. 2. Scintillations, similar to Fig. 1c, are organized by year and season (centered around solstices and equinoxes). From left to right: spring (February, March, April), summer (May, June, July), fall (August, September, October), and winter (November, December, January) months. The corresponding year for the panels in a row is labeled in the rightmost panel. Local-time differences between the occurrence peaks of strong (red) and weak (blue) scintillations are apparent in spring and summer. 
as the Sun paced toward the late phase of Solar Cycle 24 into a new solar minimum. This agrees well with previous findings that occurrence of scintillations increases with solar activity: highest at solar maximum and lowest at solar minimum (Basu et al. 1988; Prasad et al. 2012). The annual mean of F10.7 index, the solar radio flux at $10.7 \mathrm{~cm}$ in units of s.f.u., decreased from 117.5 to 69.7 during this period of time: 117.5 in 2015, 88.8 in 2016, 77.2 in 2017, 70.0 in 2018, and 69.7 in 2019. It is interesting to find that the occurrence rates of weak scintillations are somewhat similar during 2015 - 2019, especially in summer, which seems insensitive to the solar activity.

The diurnal variation of plasma drifts reveals strong eastward drifts at the nightside and apparent westward drifts at the dayside as shown in Fig. 3. In Fig. 3a, all the drift data points are shown in scatter black dots. The median drifts at given local hours are marked in red. In this set of figures, circular markers represent data points with the medians of $\mathrm{S}_{4}$ index greater than 0.5 (strong scintillation) within the hours, and square markers represent those with the medians of $\mathrm{S}_{4}$ index lower than 0.5 (strong scintillation). Strong eastward drifts of greater than $30 \mathrm{~m} \mathrm{~s}^{-1}$ often occur concurrently with strong scintillations during nighttime, while predominant westward drifts during daytime mostly correspond to weak scintillations. In Fig. 3b, drifts are color-coded by season: green for spring and fall, blue for winter, and purple for summer. Vertical drifts have been shown to reach peak amplitudes when the solar zenith angle is the smallest (in Fejer et al. 1991). The condition was met during equinox for the Jicamarca incoherent scatter radar (ISR) that the downward electric field results in prominent eastward drifts due to Fregion dynamo during nighttime (Kelley 2009).

In Fig. 3c, drifts are color-coded by solar activity level. During 2015 - 2016, the annual averages of F10.7 are greater than 80 , which is deemed higher solar activity level in this study. The data points during these two years are shown in red. The annual averages of F10.7 fall below 80 during 2017 - 2019, whose data points are shown in blue. Clear
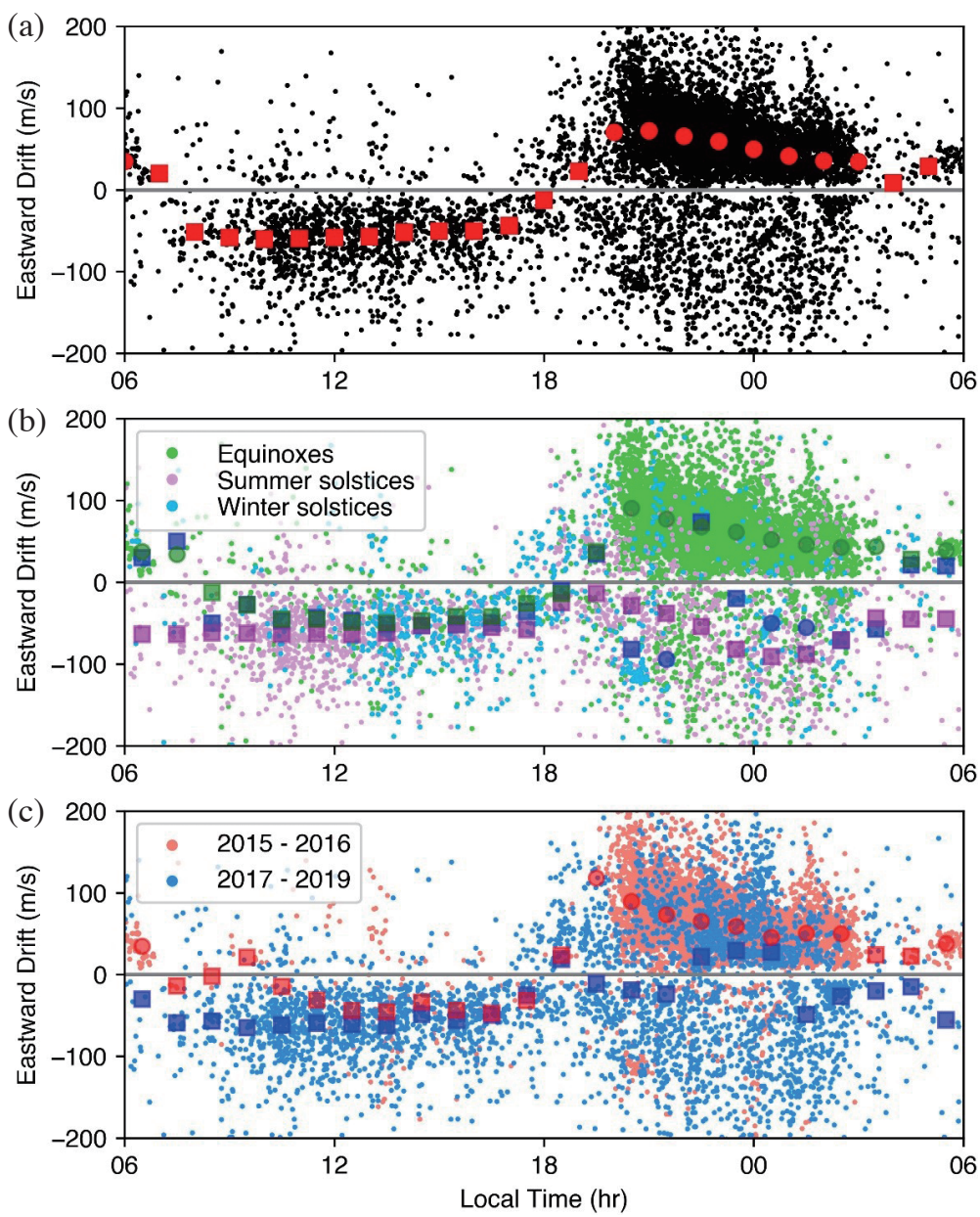

Fig. 3. The diurnal variation of plasma drifts reveals strong eastward drifts at the nightside and apparent westward drifts at the dayside. (a) Plasma drifts (black) with the medians at local hours marked in red. (b) Drifts are color-coded by season: green for spring and fall, blue for winter, and purple for summer. (c) Drifts are color-coded by solar activity level: higher level (with annual-mean F10.7 greater than 80) in red and lower solar activity (with annual-mean F10.7 lower than 80) in blue. Symbols with the corresponding hourly medians of $\mathrm{S}_{4}$ indices above 0.5 are shown as circles (strong scintillations) and that below 0.5 are shown as square (weak scintillations). 
local-time dependency of plasma drift can be observed during high solar activity years: predominant eastward drifts during nighttime and predominant westward drifts during daytime. During 2017 - 2019, when solar activity was low, no strong tendency of nighttime drifts is observed, while the daytime drifts still appear to be predominantly westward.

\section{DISCUSSION AND SUMMARY}

A valuable data set of scintillations and plasma drifts is derived from 5 years of VHF observations conducted in Pingtung, Taiwan, where is under the northern EIA region. The results show that strong scintillations $\left(\mathrm{S}_{4}>0.5\right)$ appear frequently at early nighttime in spring and fall during the high solar activity year of 2015, while weak scintillons ( $\mathrm{S}_{4}$ : 0.2 - 0.5 ) occur often at early daytime and more frequently at early nighttime in summer without obvious correlation with solar activity levels. Scintillations with frequent occurrences tend to appear at early nighttime of equinox during high solar activity years of 2015 - 2016. Over the 5 years of observations, occurrence rates of scintillations lower as the Sun paced toward the late phase of Solar Cycle 24 into a new solar minimum. The strong scintillations occur frequently at early nighttime in spring and fall during the high solar activity year of 2015, which agree well with the L-band $\mathrm{S}_{4}$ scintillations of GPS signals at the EIA region (Liu et al. 2012, 2016). The agreement suggests that the prereversal enhancement and solar activity are essential factors for scintillation occurrences (Kelley 2009). On the other hand, the weak scintillons occur frequently at early daytime and more often at early nighttime in summer without obvious correlation with solar activity, which generally are similar to the daytime $\mathrm{S}_{4}$ observed by SCINDA GPS receiving stations in low latitude region (Seif et al. 2017) and the L-band $\mathrm{S}_{4}$ scintillations of sporadic $\mathrm{E}$ (Es) at the low/middle ionosphere (Liu et al. 2012, 2016). We conclude that the observed strong and weak VHF scintillations resulted from different causals.

We also demonstrated the possibility of estimating drift velocity with the VHF data. A clear diurnal variation of drift velocities shows the eastward drifts of $\sim 50-60 \mathrm{~m} \mathrm{~s}^{-1}$ during nighttime and the westward drift of the similar magnitude during daytime. The day/night feature is more prominent during high solar activity years. In spring and fall months, the directionality of drifts is distinctly different at the dayside and nightside. The pattern of east-west horizontal VHF drifts is similar to that of the F-region east-west horizontal drifts observed by the ISR at Arecibo $\left(18.33^{\circ} \mathrm{N}\right.$, $66.75^{\circ} \mathrm{W}, 46.7^{\circ}$ magnetic dip) in the middle ionosphere, and by the ISR at Jicamarca Radio Observatory, Jicamarca, Peru $\left(11.95^{\circ} \mathrm{S}, 76.87^{\circ} \mathrm{W}, 1^{\circ}\right.$ magnetic dip), which had a maximum in eastward drifts of about $110(-50) \mathrm{m} \mathrm{s}^{-1}$ in the nighttime (daytime) (Kelley 2009). However, eastward drifts almost diminished in summer and winter months as well as in the low solar activity years of $2017-2019$. Liu et al. (2011) examined plasma depletions in the $630.0 \mathrm{~nm}$ emission over the EIA region in Taiwan during the solar maximum of 1998 - 2002 and the solar minimum of 2006 2007. They found that the equatorial plasma bubble (EPB) depletions, especially in the equinox months, are aligned along in the north-south direction and drift eastwards with velocities in the range $60-170 \mathrm{~m} \mathrm{~s}^{-1}$ in the pre-midnight period during the solar maximum year. However, EPB depletions were almost completely absent during the solar maximum year. The agreement in prominent eastward drifts between EPBs and the VHF scintillations might be due to pre-reversal enhancement (PRE) increasing in the equinox months during the solar maximum years. By contrast, decreases of PRE could drastically suppress the occurrence of scintillations and significantly modify drift velocities in the solstice months during the solar minimum years (Kelley 2009). In summary, this paper, for the first time, reports diurnal, seasonal, and solar activity variations of the horizontal east-west drift of VHF scintillations in the EIA ionosphere. Compared to tremendous cost and space associated with ISRs, VHF receivers are much more economic and mobile. This signifies the critical roles of VHF receivers and the SCINDA program in our understanding the ionospheric state and dynamics.

Acknowledgements The research at the National Central University was supported by Taiwan's Ministry of Science and Technology (MOST). Cissi Y. Lin is supported by MOST 110-2111-M-008-034-MY2 and MOST 110-2111M-008-017. This work was financially supported by the Center for Astronautical Physics and Engineering (CAPE) from the Featured Area Research Center program within the framework of Higher Education Sprout Project by the Ministry of Education (MOE) in Taiwan. The authors acknowledge the contributions of the SCINDA project, especially the collaborators at the Pingtung site. Special thanks are dedicated to Drs. L. C. Tsai, S. Y. Su, Ronald Caton, and K. M. Groves. GOES solar data are available on the NOAA SWPC website. The scintillation and drift data derived from the SCINDA raw observations are available at doi: 10.5281/ zenodo.5068329.

\section{REFERENCES}

Ackah, J. B., O. K. Obrou, Z. Zaka, M. N. Mene, and K. Groves, 2011: Study of equatorial ionospheric scintillation and TEC characteristics at solar minimum using GPS-SCINDA data. Sun and Geosphere, 6, 27-30.

Andima, G., E. B. Amabayo, E. Jurua, and P. J. Cilliers, 2018: Characterization of the low latitude plasma density irregularities observed using C/NOFS and SCINDA data. Adv. Space Res., 61, 264-273, doi: 10.1016/j. asr.2017.08.003. [Link] 
Basu, S., E. M. MacKenzie, S. Basu, E. Costa, P. F. Fougere, H. C. Carlson, and H. E. Whitney, 1987: $250 \mathrm{MHz} /$ $\mathrm{GHz}$ scintillation parameters in the equatorial, polar, and auroral environments. IEEE J. Sel. Areas Commun., 5, 102-115, doi: 10.1109/JSAC.1987.1146533. [Link]

Basu, S., E. MacKenzie, and S. Basu, 1988: Ionospheric constraints on VHF/UHF communications links during solar maximum and minimum periods. Radio Sci., 23, 363-378, doi: 10.1029/RS023i003p00363. [Link]

Basu, S., E. Kudeki, S. Basu, C. E. Valladares, E. J. Weber, H. P. Zengingonul, S. Bhattacharyya, R. Sheehan, J. W. Meriwether, M. A. Biondi, H. Kuenzler, and J. Espinoza, 1996: Scintillations, plasma drifts, and neutral winds in the equatorial ionosphere after sunset. J. Geophys.Res., 101, 26795-26809, doi: 10.1029/96ja00760. [Link]

Bhattacharyya, A., P. Gurram, B. Kakad, S. Sripathi, and S. Sunda, 2019: Signal frequency dependence of ionospheric scintillations: An indicator of irregularity spectrum characteristics. J. Geophys. Res., 124, 8081-8091, doi: 10.1029/2019ja026987. [Link]

Chandra, H. and R. G. Rastogi, 1974: Geomagnetic storm effects on ionospheric drifts and the equatorial E/sub $\mathrm{s} /$ over the magnetic equator. Indian J. Radio Space Phys., 3, 332-336.

Chen, S.-P., D. Bilitza, J.-Y. Liu, R. Caton, L. C. Chang, and W.-H. Yeh, 2017: An empirical model of L-band scintillation S4 index constructed by using FORMOSAT-3/COSMIC data. Adv. Space Res., 60, 10151028, doi: 10.1016/j.asr.2017.05.031. [Link]

Fejer, B. G., E. R. de Paula, S. A. González, and R. F. Woodman, 1991: Average vertical and zonal $\mathrm{F}$ region plasma drifts over Jicamarca. J. Geophys. Res., 96, 13901-13906, doi: 10.1029/91ja01171. [Link]

Groves, K. M., S. Basu, E. J. Weber, M. Smitham, H. Kuenzler, C. E. Valladares, R. Sheehan, E. MacKenzie, J. A. Secan, P. Ning, W. J. McNeill, D. W. Moonan, and M. J. Kendra, 1997: Equatorial scintillation and systems support. Radio Sci., 32, 2047-2064, doi: 10.1029/97rs00836. [Link]

Hlubek, N., J. Berdermann, V. Wilken, S. Gewies, N. Jakowski, M. Wassaie, and B. Damtie, 2014: Scintillations of the GPS, GLONASS, and Galileo signals at equatorial latitude. J. Space Weather Space Clim., 4, A22, doi: 10.1051/swsc/2014020. [Link]

Ji, S., W. Chen, X. Ding, and C. Zhao, 2011: Equatorial ionospheric zonal drift by monitoring local GPS reference networks. J. Geophys. Res., 116, A08310, doi: 10.1029/2010ja015993. [Link]

Joshi, L. M., L.-C. Tsai, S.-Y. Su, R. G. Caton, C.-H. Lu, and K. M. Groves, 2019: VHF scintillation and drift studied using spaced receivers in southern Taiwan. Radio Sci., 54, 455-467, doi: 10.1029/2018rs006722.
[Link]

Kelley, M., 2009: The Earth's Ionosphere: Plasma Physics and Electrodynamics, International Geophysics, Volume 96, 2nd Edition, Academic Press, USA, 576 pp.

Kil, H., P. M. Kintner, E. R. de Paula, and I. J. Kantor, 2002: Latitudinal variations of scintillation activity and zonal plasma drifts in South America. Radio Sci., 37, 6-1-67, doi: 10.1029/2001rs002468. [Link]

Liu, J. Y., P. K. Rajesh, I. T. Lee, and T. C. Chow, 2011: Airglow observations over the equatorial ionization anomaly zone in Taiwan. Ann. Geophys., 29, 749-757, doi: 10.5194/angeo-29-749-2011. [Link]

Liu, J. Y., S. P. Chen, W. H. Yeh, H. F. Tsai, and P. K. Rajesh, 2016: Worst-Case GPS Scintillations on the Ground Estimated from Radio Occultation Observations of FORMOSAT-3/COSMIC During 2007-2014. Surv. Geophys., 37, 791-809, doi: 10.1007/s10712015-9355-x. [Link]

Liu, Y.-H., C.-H. Liu, and S.-Y. Su, 2012: Global and seasonal scintillation morphology in the equatorial region derived from ROCSAT-1 in-situ data. Terr. Atmos. Ocean. Sci., 23, 95-106, doi: 10.3319/ TAO.2011.06.30.01(AA). [Link]

McNamara, L. F., R. G. Caton, R. T. Parris, T. R. Pedersen, D. C. Thompson, K. C. Wiens, and K. M. Groves, 2013: Signatures of equatorial plasma bubbles in VHF satellite scintillations and equatorial ionograms. Radio Sci., 48, 89-101, doi: 10.1002/rds.20025. [Link]

Olwendo, O. J., T. Baluku, P. Baki, P. J. Cilliers, C. Mito, and P. Doherty, 2013: Low latitude ionospheric scintillation and zonal irregularity drifts observed with GPSSCINDA system and closely spaced VHF receivers in Kenya. Adv. Space Res., 51, 1715-1726, doi: 10.1016/j. asr.2012.12.017. [Link]

Otsuka, Y., K. Shiokawa, and T. Ogawa, 2006: Equatorial ionospheric scintillations and zonal irregularity drifts observed with closely-spaced GPS receivers in Indonesia. J. Meteorol. Soc. Jpn., 84A, 343-351, doi: 10.2151/jmsj.84a.343. [Link]

Prasad, S. N. V. S., P. V. S. Rama Rao, D. S. V. V. D. Prasad, K. Venkatesh, and K. Niranjan, 2012: Morphological studies on ionospheric VHF scintillations over an Indian low latitude station during a solar cycle period (2001-2010). Adv. Space Res., 50, 56-69, doi: 10.1016/j.asr.2012.03.020. [Link]

Rastogi, R. G. and J. Mullen, 1981: Intense daytime radio wave scintillations and sporadicElayer near the dip equator. J. Geophys. Res., 86, 195-198, doi: 10.1029/ JA086iA01p00195. [Link]

Seif, A., J.-Y. Liu, A. J. Mannucci, B. A. Carter, R. Norman, R. G. Caton, and R. T. Tsunoda, 2017: A study of daytime L-band scintillation in association with sporadic $\mathrm{E}$ along the magnetic dip equator. Radio Sci., 52, 15701577, doi: 10.1002/2017rs006393. [Link] 
Singh, S. B., V. S. Rathore, A. K. Singh, and A. K. Singh, 2017: Ionospheric irregularities at low latitude using VHF scintillations during extreme low solar activity period (2008-2010). Acta Geod. Geophys., 52, 35-51, doi: 10.1007/s40328-016-0168-2. [Link]

Spatz, D. E., S. J. Franke, and K. C. Yeh, 1988: Analysis and interpretation of spaced receiver scintillation data recorded at an equatorial station. Radio Sci., 23, 347361, doi: 10.1029/RS023i003p00347. [Link]

Valladares, C. E., J. W. Meriwether, R. Sheehan, and M. A. Biondi, 2002: Correlative study of neutral winds and scintillation drifts measured near the magnetic equator. J. Geophys. Res., 107, doi: 10.1029/2001 ja000042. [Link]
Van Dierendonck, A. J., J. Klobuchar, and Q. Hua, 1993: Ionospheric scintillation monitoring using commercial single frequency C/A code receivers. Proceedings of the 6th International Technical Meeting of the Satellite Division of the Institute of Navigation (ION GPS 1993), Salt Lake City, UT, 1333-1342.

Wiens, R. H., B. M. Ledvina, P. M. Kintner, M. Afewerki, and Z. Mulugheta, 2006: Equatorial plasma bubbles in the ionosphere over Eritrea: Occurrence and drift speed. Ann. Geophys., 24, 1443-1453, doi: 10.5194/ angeo-24-1443-2006. [Link]

Yeh, K. C. and C.-H. Liu, 1982: Radio wave scintillations in the ionosphere. Proc. IEEE, 70, 324-360, doi: 10.1109/ PROC.1982.12313. [Link] 